\title{
Assessing the association between medication adherence, as defined in quality measures, and disease-state control, health care utilization, and costs in a retrospective database analysis of Medicare supplemental beneficiaries using statin medications
}

\author{
David R Axon, PhD, MPharm, MS; Shannon Vaffis, MPH, PMP; Chanadda Chinthammit, BSPharm, MS, PhD; \\ Breanne E Lott, MPH; Ann M Taylor, MPH, MCHES; Matthew Pickering, PharmD, RPh; Heather Black, PhD; \\ Terri Warholak, PhD, RPh, FAPhA; and Patrick J Campbell, PhD, PharmD, RPh
}

\section{What is already known about this subject}

- Chronic diseases such as hypercholesterolemia result in morbidity and mortality in the United States, yet adherence to statin medications can improve health outcomes.

- Medication adherence is associated with lower health care costs for many drug therapies, including cholesterol (statin) medications.

\section{What this study adds}

- This study adds to the evidence-base for Pharmacy Quality Alliance's proportion of days covered ( $\geq 80 \%$ ) adherence measure definitions, as an appropriate indirect proxy for medication adherence behavior, using a retrospective analysis of large claims database.

- This sample of Medicare beneficiaries who were adherent to statin medications, while controlling for other factors, were associated with twice the odds of having better clinical outcomes (e.g., controlled disease state), fewer health care visits, and lower total costs over the 1-year time frame compared with nonadherers, despite having higher prescription drug costs.

- Statin medication adherence was associated with costs savings for outpatient (-\$43.49 per patient per month [PMPM]), inpatient (-\$127.57 PMPM), and total (-\$157.32 PMPM) costs and higher prescription drug costs (\$12.69 PMPM) compared with nonadherence over the 1-year study period.

\section{Author affiliations}

David R Axon, PhD, MPharm, MS; Shannon Vaffis, MPH, PMP; Ann M Taylor, MPH, MCHES; and Terri Warholak, PhD, RPh, FAPhA, University of Arizona College of Pharmacy, Tucson. Chanadda Chinthammit, BSPharm, MS, PhD, University of Arizona College of Pharmacy, Tucson, and Eli Lilly and Company, Indianapolis, IN. Breanne E Lott, MPH, Mel \& Enid Zuckerman College of Public Health, University of Arizona, Tucson; Matthew Pickering, PharmD, RPh, Pharmacy Quality Alliance, Alexandria, VA; and Heather Black, PhD, Merck \& Co., Kenilworth, NJ. Patrick J Campbell, PhD, PharmD, RPh, University of Arizona College of Pharmacy, Tucson, and Pharmacy Quality Alliance, Alexandria, VA.

\section{AUTHOR CORRESPONDENCE:}

David R Axon, 520.621.5961, axon@pharmacy.arizona.edu

J Manag Care Spec Pharm 2020;26(12):1529-37

Copyright $\odot 2020$, Academy of Managed Care Pharmacy. All rights reserved. 


\section{ABSTRACT}

BACKGROUND: Adherence to medication, and related health and economic outcomes, is becoming increasingly important as populations age and as the number of Americans managing chronic conditions increases. The Pharmacy Quality Alliance (PQA) statin medication adherence measure is used in Medicare star ratings to evaluate health plan performance. Yet, limited evidence exists that investigates the association between statin medication adherence, as specified in the PQA adherence quality measure, and disease-state control, health care utilization, and costs.

OBJECTIVE: To determine the association between adherence $(\geq 80 \%$ proportion of days covered) and disease-state control, health care utilization, and health care costs for Medicare supplemental beneficiaries using statin medications eligible for inclusion in the PQA statin adherence quality measure.

METHODS: This retrospective study used a cohort of eligible beneficiaries for inclusion in the PQA statin adherence measure with low-density lipoprotein (LDL) laboratory values from IBM MarketScan Medicare Supplemental Research Databases (2009-2015). A logistic regression model assessed the association between adherence and LDL control (controlled individuals had LDL levels $\leq 100 \mathrm{mg}$ / $\mathrm{dL}$ ). Health care utilization and costs during a 1-year period, from first statin medication claim, were compared between adherent and nonadherent groups using generalized linear models with log link and negative binomial distribution (utilization) or gamma distribution (costs), adjusting for covariates. Beta coefficients were used to compute cost ratios (CR) and rate ratios (RR). Cohort characteristics were assessed using t-tests, Wilcoxon rank sum tests, or chi-square tests. An a priori alpha level of 0.001 was used.

RESULTS: The study cohort consisted of 77,174 beneficiaries, of whom $58,668(76.0 \%)$ were classified as adherent to their statin medications. After controlling for other factors, odds of diseasestate control were approximately 2 times higher among medication adherent beneficiaries compared with their nonadherent counterparts $(\mathrm{OR}=2.192 ; 95 \% \mathrm{Cl}=2.109-2.278)$. Multivariable analyses showed adherers experienced $4.7 \%$ fewer outpatient $(R R=0.953 ; 95 \%$ $\mathrm{Cl}=0.940-0.965)$ and $27.5 \%$ fewer inpatient $(\mathrm{RR}=0.725 ; 95 \% \mathrm{Cl}=0.687$ $0.766)$ visits; had $9.9 \%$ lower outpatient $(\mathrm{CR}=0.901 ; 95 \% \mathrm{Cl}=0.885$ $0.916)$ and $28.3 \%$ lower inpatient $(\mathrm{CR}=0.717 ; 95 \% \mathrm{Cl}=0.705-0.729)$ costs; $14.7 \%$ lower total costs ( $C R=0.853 ; 95 \% \mathrm{Cl}=0.838-0.868)$; and $7.0 \%$ higher prescription drug costs $(\mathrm{CR}=1.070 ; 95 \% \mathrm{Cl}=1.052-1.089)$ than nonadherers. Adherence to statin medications was associated with a reduction in total costs of $\$ 157.32$ per member per month.

CONCLUSIONS: This retrospective database analysis demonstrated that statin adherence was associated with approximately twice the odds of having a controlled disease state compared with nonadherence in a large Medicare sample. Adherent beneficiaries had fewer outpatient and inpatient visits (lower utilization), lower outpatient and inpatient costs, and lower total costs, a calculated savings of $\$ 157.32$ per member per month, despite having higher prescription drug costs. Finally, these results provide important new information by demonstrating that adherence $(\geq 80 \%)$ is associated with lower health care costs in a short (1-year) time frame.
Chronic diseases are the leading cause of disability and mortality in the United States, with 6 in 10 adults managing at least 1 chronic condition. ${ }^{1}$ Hyperlipidemia, or high cholesterol, is one of the most prevalent chronic conditions, requiring continued management with daily medication to maintain disease control. Adherence to cholesterol (statin) medications can improve short- and long-term health outcomes and lower health care utilization and costs. ${ }^{2-6}$

The Institute for Healthcare Improvement Triple Aim framework promotes 3 dimensions of health system performance improvement: improved patient care experiences, improved health of populations, and reduced per capita cost of health care. ${ }^{7}$ Operationalizing medication adherence with a standardized measure and exploring its association with individual and population health outcomes (e.g., controlled levels of low-density lipoprotein [LDL]) and economic outcomes (e.g., health care utilization and costs) provides rich, actionable evidence for health professionals, policymakers, health plan sponsors, providers, and patients to effectively manage chronic conditions.

Medication adherence-the degree that individuals take their medications as prescribed-is measurable via multiple methods. One measure uses pharmacy claims data to calculate the proportion of days covered (PDC), when patients have filled prescriptions readily available to them. The Pharmacy Quality Alliance (PQA), a multistakeholder, nonprofit health care quality organization, has developed, tested, and endorsed multiple PDC measures. The Centers for Medicare \& Medicaid Services (CMS) Star Rating System for Medicare Advantage Prescription Drug plans and standalone Prescription Drug Plans use PDC to measure health plan performance. Thus, payers and providers often use PDC to target their interventions. Despite this, the PQA PDC measures (e.g., for statins) are relatively new, and the supporting literature regarding adherence definitions used in these measures and their associations with outcomes is limited.

As the U.S. population ages, understanding chronic disease management, including the association between medication adherence, health outcomes, and economic outcomes, is becoming increasingly important. In 2016, people aged 55 years and older accounted for more than half of all U.S. health care spending (56\%), while they represented only $29 \%$ of the total population. ${ }^{8}$ To address this gap, this study assessed the association between adherence, as specified in the PQA statin medication adherence quality measure ( $\geq 80 \%$ PDC) and (a) disease-state control, (b) health care utilization, and (c) health care expenditure among beneficiaries with statin medication claims in a 1-year retrospective analysis of IBM MarketScan Medicare Supplemental Research Databases (2009-2015). 


\section{Methods}

\section{STUDY DESIGN AND DATA SOURCE}

A retrospective cohort study design involved analysis of adherence as specified in the PQA statin medication adherence quality measure and clinical and economic outcomes for a subset of beneficiaries in the IBM MarketScan Medicare Supplemental Research Databases (2009-2015). For beneficiaries covered by Medicare supplemental insurance plans in the United States, deidentified data elements included beneficiary demographics, enrollment details, medical diagnoses and procedures; laboratory values for LDL; and outpatient, inpatient, and prescription administrative claims. ${ }^{9}$ The University of Arizona Institutional Review Board approved this study.

\section{STUDY SAMPLE}

Study inclusion criteria were informed by the PQA statin medication adherence quality measure specifications. Beneficiaries aged 18 years or older at the index date were eligible for inclusion; the index date was defined as the first fill for a medication included in the PQA statin adherence measure after a 180-day baseline period. Eligible beneficiaries were included if they had continuous enrollment for 6 months before and 12 months after the index date and at least 2 prescriptions dispensed for any medication included in the PQA measure, with at least 150 days between the first and last fill during the measurement period. Beneficiaries with a diagnosis of end-stage renal disease, based on the International Classification of Diseases, Ninth Revision, Clinical Modification code of 585.6, during the measurement period were excluded. In addition to the PQA eligibility criteria, subjects needed to have laboratory value data (i.e., LDL values) available for inclusion. Included beneficiaries were followed for a 1-year measurement period.

\section{OUTCOME VARIABLES}

This study investigated the effect of adherence on diseasestate control and health care utilization and expenditure. Beneficiaries using a statin medication were considered in a controlled disease state if their LDL values were $\leq 100 \mathrm{mg} / \mathrm{dL}$. Health care utilization was calculated as the number of outpatient and inpatient visits during the measurement period. Health care expenditure was calculated for outpatient, inpatient, prescription drug, and total health care costs over 1 year, with adjustment to 2015 U.S. dollars.

\section{INDEPENDENT VARIABLE}

The key independent variable was adherence status (adherent vs. nonadherent) measured via the PQA PDC methodology for statin medications. ${ }^{10,11}$ The following statin medications were included: sitagliptin-simvastatin, atorvastatin calcium, fluvastatin sodium, lovastatin, pitavastatin calcium, rosuvastatin calcium, pravastatin sodium, simvastatin, niacin-lovastatin, ezetimibe-atorvastatin, ezetimibesimvastatin, and amlodipine besylate-atorvastatin calcium. ${ }^{12}$ PDC is the proportion of days in the study period where the treatment regimen is available to the patient as observed from pharmacy claims data. Adherence was defined as $\mathrm{PDC} \geq 80 \%$.

\section{COVARIATES}

Potential confounders or risk factors for health care utilization and expenditure were included as covariates in the statistical models. Covariates, measured during the baseline period, included age (in years at index date), gender, U.S. geographic region, insurance plan type, Deyo-Charlson Comorbidity Index (DCCI) score, disease-state control, monthly average number of chronic medications (prescription supply $\geq 28$ days), and treatment-naive status. Subjects who were "not naive" had filled a prescription for a medication included in the PQA adherence measure during the baseline period, while those who were "treatment naive" first filled their prescriptions on the index date (none during the baseline period). Statin type and dose were used to classify statin treatment intensity into 3 groups (low-, moderate-, and high-intensity statins) based on clinical guidelines. ${ }^{13}$

\section{STATISTICAL ANALYSIS}

A binomial logistic regression model assessed the association between the key independent variable (adherence status) and covariates on disease-state control. Generalized linear models (GLM) were used to assess the associations between adherence status and covariates on health care utilization and cost. A GLM with a negative binomial distribution was used to assess the association between adherence status and health care utilization. A GLM with log link and gamma distribution assessed the association between adherence status and health care expenditure. Beta coefficients from the GLM were exponentiated to compute cost ratios (CR) and rate ratios (RR) to demonstrate the difference in health care expenditures and utilization between the adherent and nonadherent groups. ${ }^{14}$ Subject characteristics were assessed using t-tests or Wilcoxon rank sum tests for continuous variables or chi-square tests for categorical variables. An a priori alpha level of 0.001 was set for the analyses. All analyses were conducted using SAS version 9.4 (SAS Institute, Cary, NC).

\section{SENSITIVITY ANALYSIS}

A sensitivity analysis was conducted among eligible beneficiaries with the LDL values requirement removed to 


\section{FIGURE 1 Cohort Flowchart Diagram (2009-2015)}

Beneficiaries (aged $\geq 18$ years) with claims for a statin medication included in the PQA cholesterol adherence measure between January 1, 2009, and December 31, 2015 $(\mathrm{N}=4,550,108)$

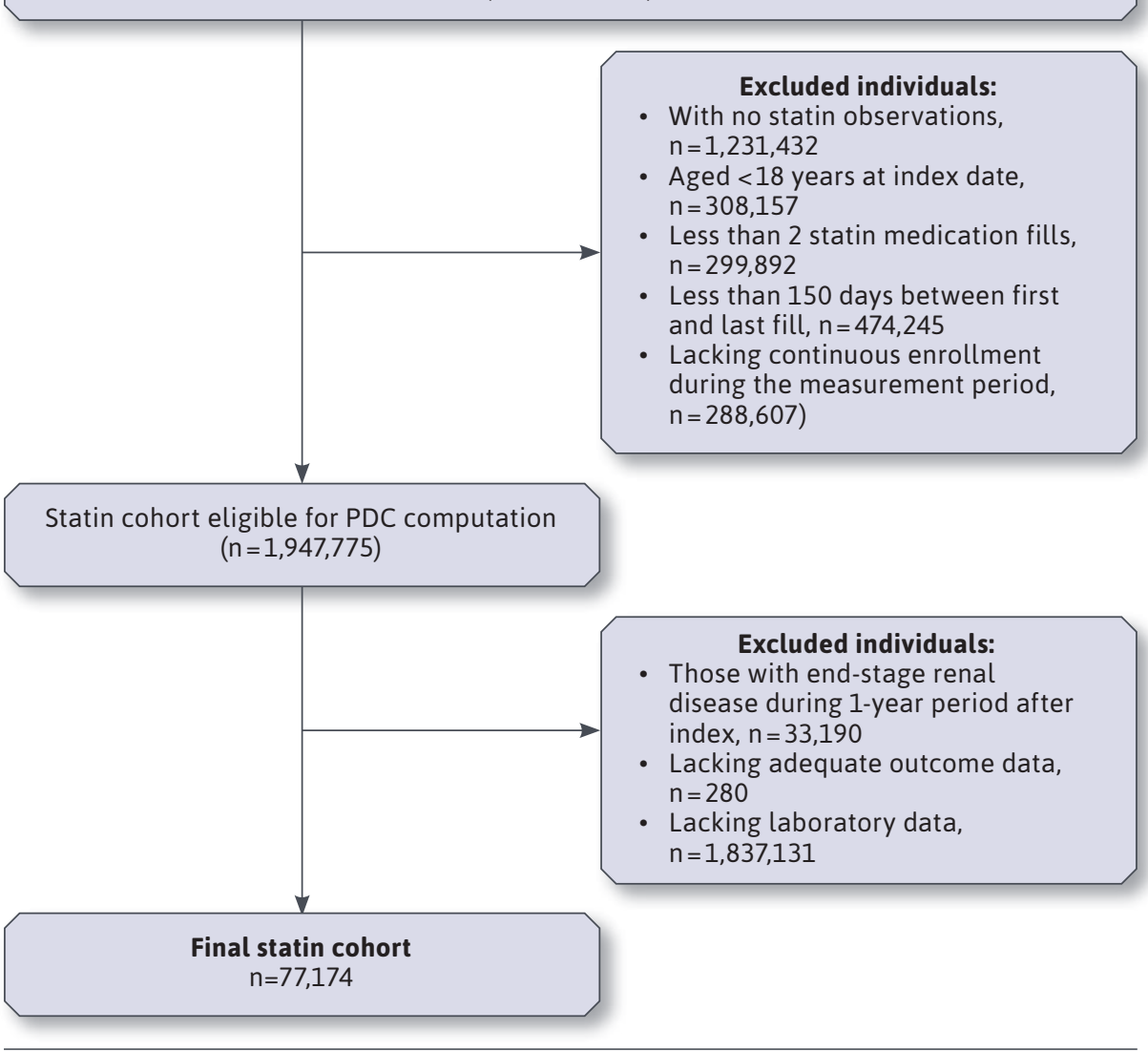

$P D C=$ proportion of days covered; $P Q A=$ Pharmacy Quality Alliance.

determine the proportion of total beneficiaries who were adherent to their statin medications and compared with the proportion of beneficiaries who did have statin lab values (and were included in this study).

\section{Results}

\section{SUBJECT CHARACTERISTICS}

Of the 4.5 million beneficiaries with prescription claims data in the IBM MarketScan Medicare Supplemental Research databases between 2009 and 2015 , a total of 77,174 beneficiaries were included in the study cohort. Figure 1 outlines the cohort selection process.

Most (76.0\%) beneficiaries were deemedadherent $(\geq 80 \%$ PDC). Adherent beneficiaries were statistically older than nonadherent beneficiaries (mean [SD] age 72.0 [6.8] and 71.8 [6.7] years respectively, $\mathrm{P}<0.001$ ), and there was a greater proportion of adherent males than females (male percentage: $50.0 \%$ and $44.6 \%$, respectively, $\mathrm{P}<0.001)$. Both groups were mostly from the West region (60.4\% and 50.0\%, respectively) and were mainly insured by health maintenance organizations (e.g., 81.5\% and $77.5 \%$, respectively). Low DCCI scores $(\leq 1)$ were more prevalent in both groups. Nonadherent beneficiaries had a higher proportion of "new" medication users than adherent beneficiaries (45.2\% vs. 22.6\%, P<0.001). At baseline, the median (interquartile range) average number of chronic medications among adherent beneficiaries was consistently higher than for their nonadherent counterparts (4.2 [3.5] vs. 3.2 [3.2], $\mathrm{P}<0.001)$. Table 1 provides detailed beneficiary demographic characteristics by adherence status.

The majority of beneficiaries were taking a moderate intensity statin (adherent 68.8\%, nonadherent 66.3\%). In the unadjusted analyses, the proportion of beneficiaries with controlled LDL levels was higher in the adherent versus nonadherent group (78.6\% vs. $61.1 \%, P<0.001)$. The mean number of outpatient visits was similar between groups, while the inpatient visits were lower among adherent beneficiaries. For adherent beneficiaries, prescription drug costs were higher, while outpatient, inpatient, and total costs were lower.

\section{EFFECT OF ADHERENCE ON DISEASE-STATE CONTROL, HEALTH CARE UTILIZATION, AND EXPENDITURE}

Adherence was associated with increased odds of having controlled LDL levels (odds ratio [OR] $=2.192 ; 95 \%$ $\mathrm{CI}=2.109-2.278)$, as well as a $4.7 \% \mathrm{re}^{-}$ duction in outpatient use $(\mathrm{RR}=0.953$; $95 \% \mathrm{CI}=0.940-0.965)$ and a $27.5 \%$ reduction in inpatient use $(\mathrm{RR}=0.725$; 95\% CI=0.687-0.766). Adherence also was associated with $9.9 \%$ lower outpatient costs $(\mathrm{CR}=0.901 ; 95 \% \mathrm{CI}=0.885$ 0.916); 28.3\% lower inpatient costs $(\mathrm{CR}=0.717 ; 95 \% \mathrm{CI}=0.705-0.729)$; and $14.7 \%$ lower total costs $(\mathrm{CR}=0.853$; $95 \% \mathrm{CI}=0.838-0.868)$, yet $7.0 \%$ higher prescription drug costs $(\mathrm{CR}=1.070$; 95\% CI=1.052- 1.089). Table 2 presents 


\section{TABLE 1 Statin Cohort Demographic Characteristics Based on Adherence Status}

\begin{tabular}{|c|c|c|c|c|}
\hline \multirow{2}{*}{$\begin{array}{l}\text { Characteristic } \\
\text { Age in years, mean (SD) }\end{array}$} & \multicolumn{2}{|c|}{$\begin{array}{c}\text { Adherent } \\
\mathrm{n}=\mathbf{5 8 , 6 6 8}(\mathbf{7 6 . 0 \% )}\end{array}$} & \multicolumn{2}{|c|}{$\begin{array}{c}\text { Nonadherent } \\
\mathrm{n}=\mathbf{1 8 , 4 9 8}(24.0 \%)\end{array}$} \\
\hline & 72.0 & $(6.8)$ & 71.8 & $(6.7)$ \\
\hline Male gender, n (\%) & 29,330 & $(50.0)$ & 8,258 & $(44.6)$ \\
\hline \multicolumn{5}{|l|}{ U.S. region, n (\%) } \\
\hline Northeast & 10,943 & $(18.7)$ & 4,204 & $(22.7)$ \\
\hline North Central & 7,444 & $(12.7)$ & 2,685 & $(14.5)$ \\
\hline South & 4,819 & $(8.2)$ & 2,357 & $(12.7)$ \\
\hline West & 35,454 & $(60.4)$ & 9,250 & $(50.0)$ \\
\hline Unknown & 13 & $(0.0)$ & 5 & $(0.1)$ \\
\hline \multicolumn{5}{|l|}{ Plan type, n (\%) } \\
\hline Comprehensive & 4,303 & $(7.3)$ & 1,677 & $(9.1)$ \\
\hline Health maintenance organization & 47,799 & $(81.5)$ & 14,336 & $(77.5)$ \\
\hline Point of service & 741 & $(1.3)$ & 272 & $(1.5)$ \\
\hline Preferred provider organization & 5,475 & $(9.3)$ & 2,057 & $(11.1)$ \\
\hline Point of service with capitation & 184 & $(0.3)$ & 115 & $(0.6)$ \\
\hline Consumer-directed health plan & 104 & $(0.2)$ & 25 & $(0.1)$ \\
\hline High-deductible health plan & 48 & $(0.1)$ & 15 & $(0.1)$ \\
\hline Unknown & 19 & $(0.0)$ & 4 & $(0.0)$ \\
\hline \multicolumn{5}{|l|}{ DCCl score, $\mathrm{n}(\%)$} \\
\hline 0 & 27,134 & $(46.2)$ & 8,332 & $(45.0)$ \\
\hline 1 & 14,691 & $(25.0)$ & 4,864 & $(26.3)$ \\
\hline 2 & 7,673 & $(13.1)$ & 2,307 & $(12.5)$ \\
\hline 3 & 4,926 & $(8.4)$ & 1,565 & $(8.5)$ \\
\hline 4 & 1,966 & $(3.4)$ & 650 & $(3.5)$ \\
\hline$\geq 5$ & 2,283 & $(3.9)$ & 783 & $(4.2)$ \\
\hline Treatment-naive category, $\mathrm{n}(\%)$ & 13,255 & $(22.6)$ & 8,359 & $(45.2)$ \\
\hline $\begin{array}{l}\text { Average number of chronic medications at } \\
\text { baseline, median (IQR) }\end{array}$ & 4.2 & $(3.5)$ & 3.2 & $(3.2)$ \\
\hline \multicolumn{5}{|l|}{ Statin medication intensity, $\mathrm{n}(\%)$} \\
\hline Low & 11,419 & $(19.5)$ & 3,104 & $(16.8)$ \\
\hline Moderate & 40,389 & $(68.8)$ & 12,266 & $(66.3)$ \\
\hline High & 6,962 & $(11.7)$ & 3,124 & $(16.9)$ \\
\hline Controlled LDL, ${ }^{\text {a }}$ (\%) & 46,127 & $(78.6)$ & 11,304 & $(61.1)$ \\
\hline \multicolumn{5}{|l|}{ Health care utilization, ${ }^{\mathrm{b}}$ mean (SD) } \\
\hline Outpatient & 15.2 & $(14.0)$ & 15.7 & $(15.1)$ \\
\hline Inpatient & 0.3 & $(0.9)$ & 0.4 & $(1.1)$ \\
\hline
\end{tabular}

continued on next page detailed information regarding the effect of adherence on disease-state control, health care utilization, and expenditure after adjusting for covariates.

\section{INCREMENTAL COST PER MEMBER PER MONTH}

To give monetary context to these adherence results, the incremental cost per member per month (PMPM) was computed based on the CR and annual average spending for each expenditure type. Adherence was associated with costs savings for outpatient (-\$43.49 PMPM), inpatient (-\$127.57 PMPM), and total (-\$157.32 PMPM) costs and higher prescription drug costs $(\$ 12.69$ PMPM). Figure 2 provides more detailed information regarding PMPM for adherent beneficiaries.

\section{SENSITIVITY ANALYSIS}

Among the 1,914,305 beneficiaries who met the eligibility criteria regardless of LDL values, 1,433,959 (74.9\%) were classified as adherent to statin medications.

\section{Discussion}

This study found that statin medication adherence during the 1-year time frame was associated with approximately twice the odds of having a controlled disease state (i.e., LDL $\leq 100$ $\mathrm{mg} / \mathrm{dL}$ ). Additionally, adherers had fewer outpatient and inpatient visits; lower outpatient, inpatient, and total costs; and higher prescription drug costs compared with nonadherers. However, these findings need to be interpreted in the context of narrowly defined eligibility criteria and the exclusion of the majority of subjects available in the dataset due to unavailable laboratory values. The inclusion of subjects with laboratory values may have led to selection bias, which may account for the high proportion of subjects classified as adherent in this study. The proportion of beneficiaries 


\section{TABLE 1 Statin Cohort Demographic Characteristics Based on Adherence Status (continued)}

\begin{tabular}{|c|c|c|}
\hline Characteristic & $\begin{array}{c}\text { Adherent } \\
n=58,668(76.0 \%)\end{array}$ & $\begin{array}{c}\text { Nonadherent } \\
n=\mathbf{1 8 , 4 9 8}(\mathbf{2 4 . 0 \% )}\end{array}$ \\
\hline \multicolumn{3}{|c|}{ Health care expenditure, ${ }^{c}$ mean (SD) } \\
\hline Outpatient & $4,827 \quad(9,027)$ & $5,255(10,070)$ \\
\hline Inpatient & $4,130 \quad(18,593)$ & $5,404(28,340)$ \\
\hline Prescription drug & $2,516 \quad(4,816)$ & $(5,141)$ \\
\hline Total & $11,473(24,301)$ & $12,825(34,453)$ \\
\hline
\end{tabular}

Note: All characteristics were significantly different between groups at $P<0.001$ except outpatient utilization $(P=0.26)$ and total expenditure $(P<0.01)$.

andividuals were considered controlled in the statin cohort if $L D L$ level was $\leq 100 \mathrm{mg} / \mathrm{dL}$.

${ }^{b}$ Outpatient utilization included laboratory tests, office visits, and other outpatient services; inpatient utilization includes inpatient admissions, emergency department use, and other inpatient services. '2015 U.S. dollars.

$D C C l=$ Deyo-Charlson Comorbidity Index; $I Q R=$ interquartile range; $L D L=$ low-density lipoprotein

classified as adherent (PDC $\geq 80 \%$ ) was high (76\%) for statin users drawn from this database, although our sensitivity analysis showed that $74.9 \%$ of statin users (regardless of the presence of LDL values) were classified as adherent to statin medications. Comparatively, Stuart et al. (2015) reported that 51.5\% of statin users met the same criteria, while Karve et al. (2009) observed a mean (SD) PDC of $72.2 \%$ (28.4\%). ${ }^{15,16}$

For this study, a dichotomous adherence definition was used, with the $80 \%$ cut-off point commonly used in adherence quality measures and research. However, a more granular measure of adherence may produce more nuanced results. Alternatively, continuous adherence measures may be used, although the results of such studies become increasingly complex to interpret. ${ }^{17}$ While the literature regarding PDC is limited, ${ }^{6}$ our findings add to the evidence base in support of using the standardized PDC adherence definitions used within quality measures. In this study, the $80 \%$ cutoff (dichotomous variable) used in the PQA statin adherence measure was informative in describing the association between statin medication adherence with disease-state control, health care utilization, and costs.

Regarding adherence and health care costs, Pittman et al. (2011) observed the lowest health care costs over an 18-month measurement period among individuals with 90\%-100\% adherence (defined using medication possession ratio), while there were significant increases in costs for each incrementally lower adherence category. ${ }^{5}$ Karve et al. found that an $81 \%$ cut-off point was appropriate for predicting increased risk of any cause- or disease-related hospitalization for patients on statin medications. ${ }^{16}$ In contrast, our study demonstrated successful reductions in health care costs (except prescription drug costs) for Medicare beneficiaries with a $\mathrm{PDC} \geq 80 \%$ in a short (1-year) time frame.

Importantly, our study adds to the literature by using patient laboratory values to assess disease-state control. Lower LDL levels have been endorsed by the American College of Cardiology/American Heart Association Task Force on Practice Guidelines in order to reduce the risk of cardiovascular events. ${ }^{13}$ In this study, adherent statin beneficiaries had better cholesterol control (78.6\%) compared with their nonadherent Medicare counterparts (61.1\%).

In multivariable analyses, adherers had roughly twice the odds of a controlled disease state than nonadherers. This finding provides additional evidence regarding the association between medication adherence and health care utilization and costs, while also highlighting the role of adherence on disease-state control during a 1-year time frame. However, given that only a small proportion of beneficiaries in our dataset had laboratory values, additional research should be conducted with different data to confirm these results. Further research is also warranted to investigate the effect of adherence on better diseasestate control over longer time periods.

In multivariable models, adherent statin users exhibited lower outpatient and inpatient utilization, outpatient and inpatient expenditure, lower total expenditure, and higher drug costs. Higher drug costs for adherers $(+7 \%$ change) was offset by lower outpatient costs $(-9.9 \%$ change) and inpatient costs $(-28.3 \%$ change), resulting in a $14.7 \%$ lower total expenditure compared with nonadherers.

The current findings are consistent with other research on statin therapy adherence. ${ }^{4}$ In our study, we assessed PDC based on available prescription claims data. Future studies could further investigate the association of adherence on outcomes after accounting for any differences in PDC as a result of inpatient hospitalization.

In this study, inclusion of Medicare beneficiaries is very timely given this rapidly expanding population and increased proportion of total U.S. health care expenditures. This is especially important in that medication adherence is associated with lower incremental health expenditures (\$157.32 PMPM), thus, providing 


\section{TABLE 2 Results of GLM on Disease-State Control, Health Care Utilization, and Expenditure}

\begin{tabular}{l|c|c|c}
\hline $\begin{array}{l}\text { Disease-State } \\
\text { Control }^{\text {a }}\end{array}$ & Odds Ratio & $\mathbf{9 5 \% ~ C l}$ & \\
\hline Controlled LDL $^{\text {Utilization }}{ }^{\text {b }}$ & 2.192 & $2.109-2.278$ & \\
\hline Outpatient $^{\text {Risk Ratio }}$ & 0.953 & $\mathbf{9 5 \% ~ C l}$ & \% Change \\
\hline Inpatient & 0.725 & $0.687-0.766$ & -27.5 \\
\hline Expenditure $^{\text {d }}$ & Cost Ratio & $\mathbf{9 5 \% ~ C l}$ & \% Change \\
\hline Outpatient & 0.901 & $0.885-0.916$ & -9.9 \\
\hline Inpatient & 0.717 & $0.705-0.729$ & -28.3 \\
\hline Prescription drug & 1.070 & $1.052-1.089$ & 7.0 \\
\hline Total expenditure & 0.853 & $0.838-0.868$ & -14.7 \\
\hline
\end{tabular}

Individuals were considered controlled in the statin cohort if LDL level was $\leq 100 \mathrm{mg} / \mathrm{dL}$.

${ }^{b} G L M$ with log link and negative binomial distribution adjusted for age, gender plan type, region, $\mathrm{CCl}$ score, medication use status, average number of chronic medications at baseline per month, and average number of statin mediations during study period per month.

c\% Change =adherent group percent difference compared with nonadherent group.

${ }^{d}$ GLM with log link and gamma distribution adjusted for age, gender, plan type, region, $D C C l$ score, medication use status, average number of chronic medications at baseline per month, and average number of statin mediations during study period per month.

$\mathrm{DCCl}=$ Deyo-Charlson Comorbidity Index; $G L M=$ generalized linear model; $L D L=$ low-density lipoprotein.

opportunities for development of improved interventions, policy, and health services that align with the Triple Aim framework's criteria regarding cost-effectiveness, while remaining clinically and personally relevant for beneficiaries. For instance, low-cost strategies to improve adherence and decrease health care costs may include medication conversion from 30- to 90-day supplies, mail-order versus community pharmacy prescription refill services, pharmacist-provided medication management and adherence counseling, and adoption of medication-monitoring devices. ${ }^{18,19}$

\section{LIMITATIONS}

Although this study involved a large cohort of Medicare beneficiaries taking statin medications drawn from an extensive database, it also had some limitations. First, use of administrative health insurance claims data, intended for reimbursement purposes, has the potential for billing, coding, and misclassification errors and only provides an indirect measure of medication adherence (i.e., whether a prescription was filled rather than confirming that the medication was taken correctly by the beneficiary).

Second, most beneficiaries with a prescription drug claim and a calculated PDC lacked laboratory values and were excluded from the final analysis (94.3\%, $\mathrm{n}=1,837,131 / 1,947,775)$.

Third, multiple other types of bias (i.e., selection, healthy user/adherer, and immortal time) may have been present. Although multivariable analyses accounted for differences between adherent and nonadherent groups, covariates were limited to beneficiaries who had administrative claims, so potential confounding may remain because of unobserved demographic and clinical characteristics. Further, while statistically significant, the differences between groups were small, so the effects could potentially be attributed to the large sample sizes. To reduce the risk of immortal time bias, individuals were categorized as "treatment-naive" or "non-naive" users; however, it is possible that medication exposure occurred before the study period.

Fourth, overestimation of total health care expenditures may have occurred because of inclusion of costs beyond the disease state; costs incurred during the study period that were later reversed; and costs incurred before the study period that were reversed during the 1-year study period.

Finally, the dataset provided a convenience sample of beneficiaries, and patients with certain higher-cost conditions (e.g., liver disease, cancer, and receiving palliative care) were included in the analysis, while others (e.g., endstage renal disease) were excluded. Thus, it is not possible to generalize these results to other populations (e.g., those with other or no insurance or patients with other chronic conditions).

\section{Conclusions}

This retrospective database analysis showed that beneficiaries who were adherent to statin medications had approximately twice the odds of having a controlled disease state compared with their nonadherent counterparts. Additionally, adherence to statin medications among this Medicare population, within a 1-year time frame, was associated with lower outpatient and inpatient visits; lower outpatient, inpatient, and total costs; and higher prescription drug costs. Finally, these results add important information to the evidence base by demonstrating that greater adherence $(\geq 80 \%$ PDC) can reduce health care costs in a short time frame. 


\section{FIGURE 2 Adherence Incremental Cost Per Member Per Month}

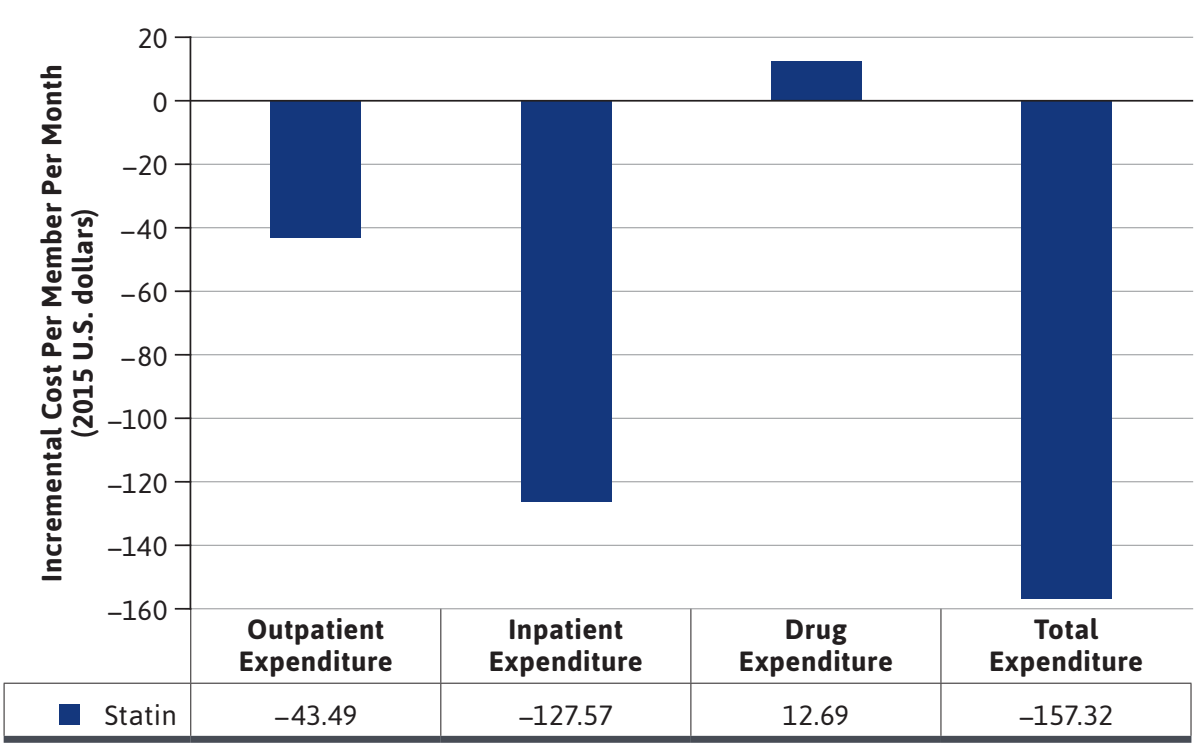

\section{DISCLOSURES}

Funding for this study was provided by Pharmacy Quality Alliance; Merck \& Co. (Kenilworth, NJ); and SinfoniaRx. All authors except Pickering and Black were employed by the University of Arizona College of Pharmacy or the Mel \& Enid Zuckerman College of Public Health at the time of this study. Pickering is employed by the Pharmacy Quality Alliance, and Black is employed by Merck \& Co. Chinthammit also reports employment with Eli Lilly and Company, and Campbell reports employment with the Pharmacy Quality Alliance. Axon reports grants from Arizona Department of Health Services, unrelated to this work. Warholak reports grants from Novartis and the Arizona Department of Health Services, unrelated to this work.

This research was presented as a poster at the International Society for Pharmacoeconomics and Outcomes Research (ISPOR) Annual Meeting 2019, May 18-22, 2019, in New Orleans, LA.

\section{REFERENCES}

1. Centers for Disease Control and Prevention. National Center for Chronic Disease Prevention and Health Promotion (NCCDPHP). September 19, 2019. Accessed October 22, 2020. https://www.cdc.gov/ chronicdisease/index.htm
2. DiMatteo MR, Giordani PJ, Lepper HS, Croghan TW. Patient adherence and medical treatment outcomes: a meta-analysis. Med Care. 2002;40(9):794-811.

3. Osterberg L, Blaschke T. Adherence to medication. N Engl J Med. 2005;353(5):487-97.

4. Roebuck MC, Liberman JN, Gemmill-

Toyama M, Brennan TA. Medication adherence leads to lower health care use and costs despite increased drug spending. Health Aff (Millwood). 2011;30(1):91-99.

5. Pittman DG, Chen W, Bowlin SJ, Foody JM. Adherence to statins, subsequent healthcare costs, and cardiovascular hospitalizations. Am J Cardiol. 2011;107(11):1662-66.

6. De Vera MA, Bhole V, Burns LC, Lacaille D. Impact of statin adherence on cardiovascular disease and mortality outcomes: a systematic review. Br J Clin Pharmacol. 2014;78(4):684-98.

7. Institute for Healthcare Improvement. IHI Triple Aim Initiative. 2019. Accessed October 22, 2020. http://www.ihi.org/ Engage/Initiatives/TripleAim/Pages/ default.aspx
8. Agency for Healthcare Research and Quality. Medical Expenditure Panel Survey. 2016. Accessed October 22, 2020. https://meps.ahrq.gov/mepsweb/

9. Adamson DM, Chang S, Hansen LG. Health research data for the real world: the MarketScan databases. Thompson Healthcare. January 2005. Accessed October 22, 2020. https://www.researchgate.net/publication/281570301_Health_ research_data_for_the_real_world_ The MarketScan databases

10. Pharmacy Quality Alliance. PQA measures overview. Accessed October 22, 2020. https://www.pqaalliance.org/ assets/Measures/2020 PQA Measures Overview.pdf

11. Nau DP. Proportion of days covered (PDC) as a preferred method of measuring medication adherence. June 25, 2012. Accessed October 22, 2020. https://www. researchgate.net/publication/273505401_ Cost-effectiveness Analysis of LDL cholesterol-Lowering Therapy in Hypertensive_Patients_with_Type2 Diabetes in Korea Single-Pill Regimen AmlodipineAtorvastatin versus_Double-Pill_Regimen_Amlodipine_/ fulltext/55d8d67908aed6a199a88e96/ Cost-effectiveness-Analysis-of-LDLcholesterol-Lowering-Therapy-inHypertensive-Patients-with-Type-2Diabetes-in-Korea-Single-Pill-RegimenAmlodipine-Atorvastatin-versus-DoublePill-Regimen-Amlodipine.pdf

12. Centers for Medicare \& Medicaid Services. NHE fact sheet. April 26, 2019. Accessed October 22, 2020. https://www. cms.gov/research-statistics-data-andsystems/statistics-trends-and-reports/ nationalhealthexpenddata/nhe-factsheet.html

13. Stone NJ, Robinson JG, Lichtenstein AH, et al. 2013 ACC/AHA Guideline on the treatment of blood cholesterol to reduce atherosclerotic cardiovascular risk in adults: a report of the American College of Cardiology/American Heart Association Task Force on Practice Guidelines. J Am Coll Cardiol. 2014;63(25 Pt B):2889-934. 
14. Halvorsen R, Palmquist R. The interpretation of dummy variables in semilogarithmic equations. Am Econ Rev. 1980;70(3):474-75.

15. Stuart BC, Dai M, Xu J, Loh FH, Dougherty J. Does good medication adherence really save payers money? Med Care. 2015;53(6):517-23.
16. Karve S, Cleves MA, Helm M, Hudson TJ, West DS, Martin BC. Good and poor adherence: optimal cut-point for adherence measures using administrative claims data. Curr Med Res Opin. 2009;25(9):2303-10.

17. Baumgartner PC, Haynes R, Hersberger $\mathrm{KE}$, Arnet I. A systematic review of medication adherence thresholds dependent of clinical outcome. Front Pharmacol. 2018;9:1290.
18. Cutrona SL, Choudhry NK, Fischer MA, et al. Modes of delivery for interventions to improve cardiovascular medication adherence: a systematic review. Am J Manag Care. 2010;16(12):929-42.

19. Viswanathan M, Golin CE, Jones CD, et al. Interventions to improve adherence to self-administered medications for chronic diseases in the United States: a systematic review. Ann Intern Med. 2012;157(11):785-95. 